\title{
Function and evolution of microRNAs in eusocial Hymenoptera
}

\author{
Eirik Søvik ${ }^{1}$, Guy Bloch ${ }^{2}$ and Yehuda Ben-Shahar ${ }^{1 *}$ \\ ${ }^{1}$ Department of Biology, Washington University in St. Louis, St. Louis, MO, USA, ${ }^{2}$ Department of Ecology, Evolution, and \\ Behavior, The Alexander Silberman Institute of Life Sciences, The Hebrew University of Jerusalem, Jerusalem, Israel
}

The emergence of eusociality ("true sociality") in several insect lineages represents one of the most successful evolutionary adaptations in the animal kingdom in terms of species richness and global biomass. In contrast to solitary insects, eusocial insects evolved a set of unique behavioral and physiological traits such as reproductive division of labor and cooperative brood care, which likely played a major role in their ecological success. The molecular mechanisms that support the social regulation of behavior in eusocial insects, and their evolution, are mostly unknown. The recent whole-genome sequencing of several eusocial insect species set the stage for deciphering the molecular and genetic bases of eusociality, and the possible evolutionary modifications that led to it.

OPEN ACCESS

Edited by:

Greg J. Hunt,

Purdue University, USA

Reviewed by:

Darren E. Hagen,

University of Missouri, USA

Roberto Bonasio,

University of Pennsylvania, USA

*Correspondence:

Yehuda Ben-Shahar.

Department of Biology, Washington

University in St. Louis, Campus

Box 1137, One Brookings Drive,

St. Louis, MO 63130, USA

benshahary@wustl.edu

Specialty section:

This article was submitted to Evolutionary and Population Genetics, a section of the journal

Frontiers in Genetics

Received: 23 March 2015

Accepted: 14 May 2015

Published: 27 May 2015

Citation:

Søvik E, Bloch G and Ben-Shahar Y

(2015) Function and evolution of microRNAs in eusocial

Hymenoptera.

Front. Genet. 6:193.

doi: 10.3389/fgene.2015.00193
Studies of mRNA expression patterns in the brains of diverse eusocial insect species have indicated that specific social behavioral states of individual workers and queens are often associated with particular tissue-specific transcriptional profiles. Here, we discuss recent findings that highlight the role of non-coding microRNAs (miRNAs) in modulating traits associated with reproductive and behavioral divisions of labor in eusocial insects. We provide bioinformatic and phylogenetic data, which suggest that some Hymenoptera-specific miRNA may have contributed to the evolution of traits important for the evolution of eusociality in this group.

Keywords: miRNA, Aculeata, Hymenoptera, eusociality, non-coding RNAs

\section{Introduction}

Most insect species are solitary, and behavioral interactions with conspecifics are primarily restricted to reproductive behaviors such as male-female courtship and male-male competition. This is in sharp contrast to social insects, where groups of genetically related individuals often live together in a colonial lifestyle. The size and stability of these colonies vary from a few individuals sharing a nest for a short period of time, to large perennial colonies composed of thousands of individuals (Hölldobler and Wilson, 2009). The most advanced form of animal social organization is termed "eusociality" (Crespi and Yanega, 1995), marked by the presence of sterile workers that often forgo own reproduction in order to support the reproduction of other colony members. Although eusociality is relatively rare in most taxonomic animal lineages, eusocial species have been immensely successful. Current projections estimate eusocial insects to represent the largest proportion of the global animal biomass (Hölldobler and Wilson, 2009). Although the reasons for this remarkable success are not well-understood, it is commonly assumed that the social lifestyle of these animals must have played a major role in their current ecological dominance (Wilson, 1990). For example, it is thought that specialization in task performance (division of labor) amongst eusocial workers enables colonies to maximize the exploitation of their environment. In contrast, 
solitary insects have to multitask independent activities, including foraging and brood rearing (Wilson, 1985).

The recent sequencing of genomes from diverse social and solitary Hymenoptera clades offers a unique opportunity for identifying genome-level molecular events that may have supported the emergence of specific traits associated with the evolution of eusociality ("eusocial traits"). The ability to compare whole-genome sequences, gene expression patterns, and other molecular properties of species with diverse forms of social lifestyles, has generated novel mechanistic and evolutionary insights into these complex behaviors. This approach has been used most successfully in studies of the division of labors in worker tasks (Smith et al., 2008) and reproduction (Schwander et al., 2010), both of which are hallmarks of eusociality (Wilson, 1985). To date, the efforts to decipher the evolution of eusocial traits, and the mechanisms that support them, have focused on protein-coding genes (Keller and Ross, 1998; Page and Amdam, 2007; Fischman et al., 2011; Woodard et al., 2011). In contrast, how non-coding regulatory RNAs may have played a role in the evolution of eusociality is understudied. Here, we examine the emerging role of an important class of small, non-coding RNAs, which are collectively referred to as "microRNAs" (miRNAs), in regulating social behaviors. We discuss their possible role in regulating eusocial traits in social Hymenoptera at the developmental, physiological, and evolutionary time scales.

\section{miRNAs: History and Background}

During the early days of the molecular biology revolution, the majority of research on gene regulation was limited to transcriptional mechanisms of protein coding genes as originally defined by the "Central dogma of molecular biology" (Crick, 1970). However, the discovery of the regulatory function of non-coding RNAs indicated that the early views on gene regulation and their associated phenotypic outcomes, were oversimplified and required major revisions to the dogma. We now know that in addition to transcriptional regulation (Lee and Young, 2000; Yan et al., 2015), gene functions are also regulated by factors such as post-transcriptional RNA editing (Gott and Emeson, 2000), mRNA splicing (Breitbart et al., 1987), RNA degradation (Bushati and Cohen, 2007), and diverse post-translational protein modifications (Braakman and Bulleid, 2011). More recently, regulatory non-coding RNAs have also emerged as important factors that regulate phenotypic variation via diverse molecular mechanisms (Qureshi and Mehler, 2012; Bonasio and Shiekhattar, 2014).

miRNAs are short (18-24 nucleotides) non-coding RNAs, which in animals seem to act primarily by repressing protein translation via interaction with the $3^{\prime} \mathrm{UTR}$ of mRNAs (Figure 1). miRNAs were first discovered in the nematode Caenorhabditis elegans, where the miRNA cel-lin-4 was shown to be necessary for the temporal timing of key developmental events (Lee et al., 1993). Because of their short length and the nature of their molecular interaction with mRNA targets, it has been hypothesized that a single miRNA can potentially regulate the function of multiple protein-coding genes (Bartel, 2009), and

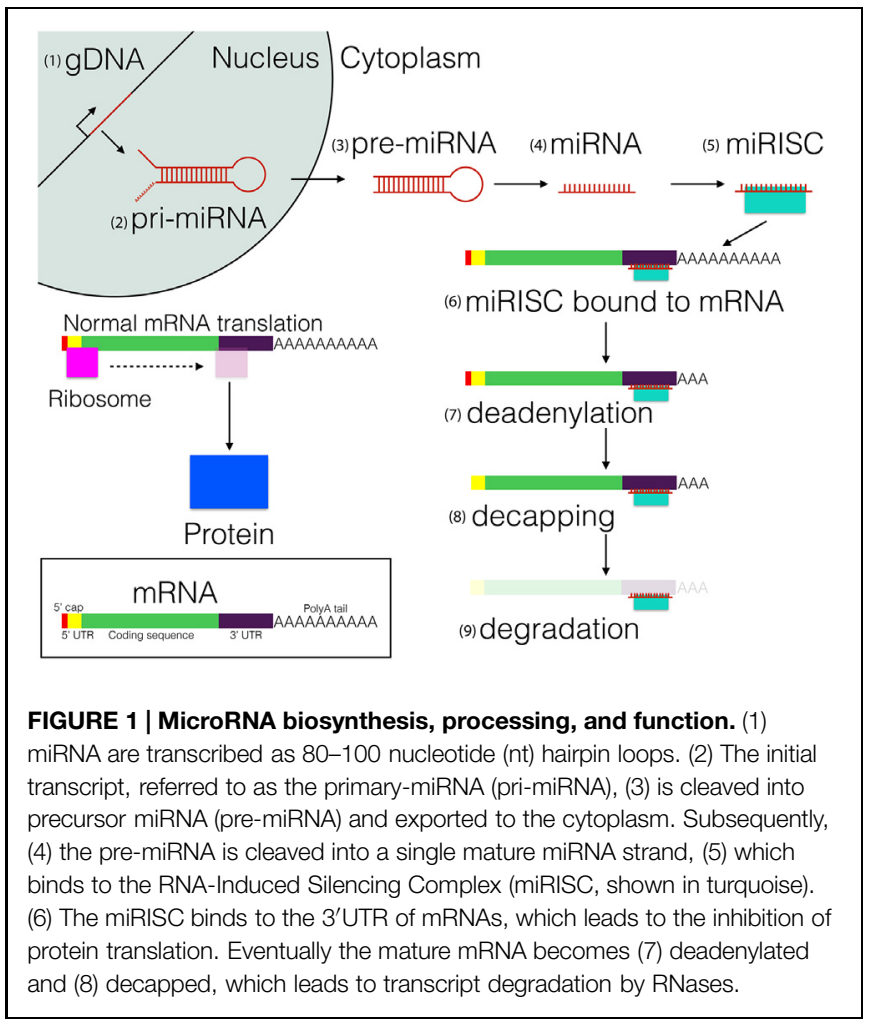

thus act as a pleiotropic genetic factor (Bartel, 2004). It is estimated that between one and two thirds of mRNAs encoded by animal genomes are regulated by miRNAs (Berezikov, 2011). As a result, it is likely that miRNAs play some roles in the regulation of most biological processes in animal cells (Bushati and Cohen, 2007).

\section{miRNAs in Development and Function of Nervous Systems}

Various miRNAs have been implicated in neuronal development (Alvarez-Garcia and Miska, 2005; Wienholds and Plasterk, 2005). There is evidence that miRNAs play important roles in fine tuning the temporal and spatial regulation of protein translation during development (Aboobaker et al., 2005; Wienholds et al., 2005). For example, miRNAs have been shown to affect canonical signaling pathways that are important for nervous system development, such as the MAPK and Notch signaling pathways (Lai et al., 2005; Chiba, 2006; Louvi and Artavanis-Tsakonas, 2006; Paroo et al., 2009; Zhu et al., 2010). It has been hypothesized that in these essential developmental pathways, miRNAs reduce the impact of stochastic variability in mRNA transcript levels on actual protein levels, which subsequently buffers the effects of environmental perturbations on cellular functions (Wu et al., 2009). Thus, some miRNAs evolved to maintain the robust association between gene expression patterns and fixed developmental traits (Peterson et al., 2009).

In contrast to their role on constraining plasticity during development, miRNAs seem to play a role in enhancing plasticity 
in the context of behavior and neuronal functions. This has been demonstrated in several recent studies, which implicated multiple miRNA genes in the regulation of neuronal plasticity (Fiore et al., 2011; Siegel et al., 2011; McNeill and Van Vactor, 2012). For example, $m i R-132$ and $m i R-134$ have been implicated in the growth and pruning of mammalian dendritic spines (Schratt et al., 2006; Impey et al., 2010), miR-133b in neurotransmitter vesicle size (Kim et al., 2007), and others in different aspects of neuronal plasticity (Schratt, 2009).

Given the emerging importance of miRNAs for neuronal plasticity, it is perhaps not surprising that distinct miRNA genes have been implicated in the regulation of behavioral plasticity as well, including entrainment of the circadian clock in mammals ( $\mathrm{Na}$ et al., 2009; Bartok et al., 2013), positive and negative responses to specific odors in Drosophila (Li et al., 2013), and the social response to unfamiliar conspecifics in mice (Gascon et al., 2014). Specific miRNA genes have also been implicated in processes associated with learning and memory, including in social insects. For example, expression levels of several miRNAs are associated with spatial learning (Qin et al., 2013), and long-term olfactory memory (Cristino et al., 2014) in the honey bee. In addition, studies in Drosophila melanogaster showed that blocking the action of dme-miR$276 a$ in the mushroom bodies, a key neuroanatomical structure necessary for many cognitive functions (Heisenberg, 2003), leads to inhibition of long-term olfactory memory formation via direct interaction with the dopamine receptor DopR (Li et al., 2013).

In addition to neuronal functions of miRNAs, some miRNAs can also affect behavior via their actions in in non-neuronal tissues. For example, manipulations of the expression of $m i R$ 184 is implicated it in the synthesis and release of insulin (Morita et al., 2013), a conserved and ubiquitously important neuroendocrine factor that is secreted from non-neuronal cells in all animal lineages (Ament et al., 2008; Wolschin et al., 2011).

\section{The Possible Role of miRNAs in the Regulation of Traits Associated with Eusociality}

\section{Developmental Plasticity: Caste Differentiation}

The completion of the honey bee genome revealed many conserved candidate miRNAs (Weinstock et al., 2006). Because of the known functions of miRNAs in the regulation of various developmental processes, it has been suggested that miRNAs are likely to contribute to the developmental processes of reproductive caste (queen-worker) differentiation (Weaver et al., 2007; Bonasio et al., 2010). In this context, it was recently reported that the expression level of the miRNA ame-miR-71 is higher in workers relative to queens during the pupal stage (Weaver et al., 2007). A subsequent study revealed that many additional miRNAs are differentially expressed between larvae that are destined to develop as either queens or workers (Shi et al., 2014). These differences in miRNA expression levels are consistent with the hypothesis that miRNAs are involved in the regulation of caste determination and differentiation. However, functional analyses of these miRNAs is needed to establish genetic causation between changes in the expression of specific miRNAs and the development of reproductive traits.

In contrast to species such as the honey bee, in which caste differentiation occur early during larval development, in some eusocial species such as the ant Harpegnathos saltator, females retain the potential to become reproductive individuals (gamergates) throughout life. Although gamergates are morphologically worker-like, they reproduce and behave like a queen following the loss of the primary queen (Peeters et al., 2000). In this species, the transition of workers into gamergates is associated with a significant reduction in the global expression levels of several miRNA genes (Bonasio et al., 2010). How global miRNA down-regulation occurs, and why it might be important for the regulation of reproductive division of labor in this species, are not yet known.

Surprisingly, recent reports suggest that exogenous miRNAs can also affect reproductive caste-determination in honey bees. Guo et al. (2013) reported that miRNAs are present in the honey bee larval food. A comparison of short RNAs found in worker food versus "royal jelly" (food that induces queen development) indicated that the overall amount of miRNAs that are fed to worker-destined larvae is significantly higher than in food given to queen-destined larvae. Furthermore, queen-destined larvae that were fed with royal jelly supplemented with the worker-enriched miRNA ame-miR-184 developed some workerlike morphologies (e.g., smaller body and shorter wings). This remarkable finding suggests that in honey bees, the consumption of exogenous miRNAs could play an important role in the differentiation of totipotent larvae into either sterile workers or reproductive queens. In this context, the conserved role of $m i R-184$ in the regulation of neuroendocrine functions across different animal taxa (Morita et al., 2013) is particularly alluring. In agreement with this hypothesis, genetic pathways that are targeted by $m i R-184$ in mammals are also important for queen versus worker differentiation in bees (Wolschin et al., 2011; Foret et al., 2012), suggesting that perhaps these observed effects of $m i R-184$ are conserved to the same pathways across mammals and insects.

\section{Behavioral Plasticity: Division of Labor}

One of the best-studied aspects of eusociality is the division of labor between workers. In some eusocial insects, such as the honey bee, division of labor relates to age (Robinson, 1992; Naug and Gadagkar, 1998; Kim et al., 2012). Young worker bees (typically $<14$ days of age) typically perform in-hive tasks, such as brood care ("nursing") or food handling, and later in life (typically at around 3 weeks of age) they transition to foraging outside the hive. This well-characterized form of behavioral development has emerged as an excellent model for the molecular mechanisms involved in social behavioral plasticity (Robinson et al., 1997, 2005; Denison and Raymond-Delpech, 2008; Bloch and Grozinger, 2011). Gene expression studies, mostly using brain tissue, have demonstrated that division of labor in honey bees, and several other eusocial species, is associated with taskspecific mRNA transcriptional profiles (Whitfield et al., 2003; 
Adams et al., 2008; Daugherty et al., 2011; Liu et al., 2011; Oxley et al., 2014).

Three recent studies also examined the possible association between changes in brain miRNAs transcript levels and division of labor in honey bees (Behura and Whitfield, 2010; Greenberg et al., 2012; Liu et al., 2012). All three studies found that the expression levels of several miRNAs are upregulated in the brains of foragers relative to bees that perform in-hive duties (Table 1).

The association of miRNA transcript levels with specific behavioral states in colonies of eusocial insects is not limited to reproductive and worker divisions of labor. For example, reproductive queens in diverse eusocial species mate only once in their lifetime (Woyke, 1955). In honey bees, newly eclosed virgin queens (gynes) leave the hive for their sole "nuptial flight" during which they copulate with 10-20 males. After mating, they spend the rest of their lives laying eggs inside the hive. Thus, virgin and mated queens represent two distinct behavioral and physiological states (Winston, 1987). A recent study of the miRNA transcriptome in virgin and mated honey bee queens identified two different genes (ame-miR-124 and ame-miR-275), which are differentially expressed in virgin and mated queens (Wu et al., 2014). While the precise function of these miRNAs

TABLE 1 | microRNAs that are differentially expressed in honey bee foragers and nurses.

\begin{tabular}{|c|c|c|c|}
\hline miRNAs & $\begin{array}{l}\text { Behura and } \\
\text { Whitfield } \\
\text { (2010) }\end{array}$ & Greenberg et al. (2012) & Liu et al. (2012) \\
\hline ame-let-7 & Nurses & & Nurses \\
\hline ame-Bantam & & Foragers & \\
\hline ame-miR-9 & Foragers & & \\
\hline ame-miR-12 & Foragers & & \\
\hline ame-miR-13a & Nurses & & \\
\hline ame-miR-13b & Nurses & & Foragers* \\
\hline ame-miR-14 & Nurses & & \\
\hline ame-miR-31a & & & Nurses \\
\hline ame-miR-92a & Foragers & & Foragers \\
\hline ame-miR-124 & Nurses & & \\
\hline ame-miR-133 & & & Foragers \\
\hline ame-miR-184 & & Foragers & \\
\hline ame-miR-210 & Foragers & & Foragers \\
\hline ame-miR-219 & Foragers & & \\
\hline ame-miR-263 & Foragers & & \\
\hline ame-miR-275 & & & Nurses \\
\hline ame-miR-276 & Nurses & & \\
\hline ame-miR-278 & & & Foragers \\
\hline ame-miR-279 & & & Nurses \\
\hline ame-miR-283 & Foragers & & \\
\hline ame-miR-2796 & & Foragers & \\
\hline
\end{tabular}

miRNAs that were differentially expressed in at least two of the studies are highlighted in red. Denoted worker group (foragers/nurses) expressed significantly higher levels relative to the other group. Behura and Whitfield (2010) measured expression of pri-miRNA using qRT-PCR, Liu et al. (2012) relied on RNA sequencing of mature miRNA, while Greenberg et al. (2012) measured mature miRNA using northern blots. *qRT-PCR analysis showed a trend that was opposite to the RNA-seq data. in honey bees is not known, previous reports indicate that miR-124 is an evolutionary conserved, brain-enriched miRNA that plays a role in neural development and plasticity in invertebrates, birds, and mammals (Cao et al., 2007; Makeyev et al., 2007; Rajasethupathy et al., 2009), and more specifically in the development and function of the peripheral sensory system in C. elegans (Clark et al., 2010). miR-275 is also conserved across insects, and has been implicated in the regulation of egg laying behavior in Aedes aegypti (Bryant et al., 2010). Wu et al. (2014) speculated that the upregulation of ame-miR-124 miRNA in virgin queens might be related to the modulation of sensory and/or other neuronal functions associated with mating behaviors, while the increased expression of ame-miR-275 in mated queens might be important for the newly mated queens to initiate egg-laying behavior.

\section{A Case for the Possible Role of miRNAs in the Evolution of Eusociality}

Why eusociality evolved multiple times within Hymenoptera but is rare in other insect orders is still a mystery. Several evolutionary models have attempted to explain this phenomenon by proposing various ultimate selective forces that may have driven the repeated rise of eusocial traits in this insect order (Hamilton, 1964; Andersson, 1984; Nowak et al., 2010). Although the regulation of phenotypes associated with eusociality has been independently linked to key regulatory pathways such as insulin and juvenile hormone signaling (Page and Amdam,

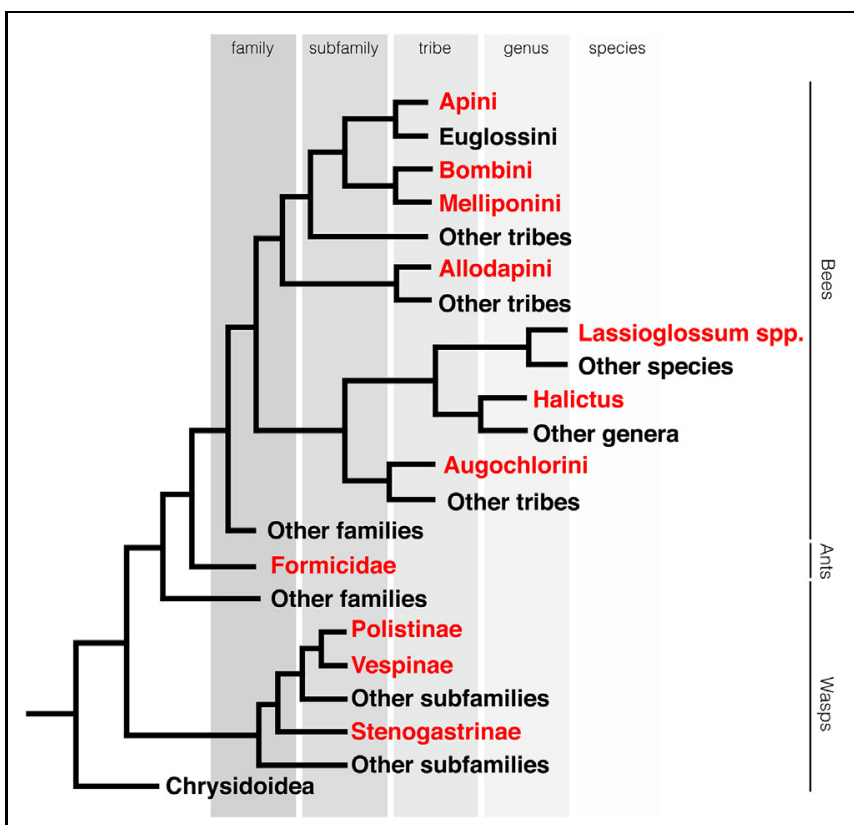

FIGURE 2 | Eusociality evolved multiple times in hymenoptera.

Phylogeny of the Aculeata. Clades containing eusocial species highlighted in red. Phylogeny is based on Danforth et al. (2013) and Johnson et al. (2013). Each branch represents the lowest taxonomic classification level that is solely comprised of eusocial species. 
TABLE 2 | Genomes analyzed.

\begin{tabular}{|c|c|c|c|c|}
\hline Order & Species & Common name & Eusocial & NCBI BioProject ID \\
\hline Ixodida & Ixodes scapularis & Deer tick & No & 34667 \\
\hline Hemiptera & Acyrthosiphon pisum & Pea aphid & No & 29489 \\
\hline Coleoptera & Tribolium castaneum & Red flour beetle & No & 15718 \\
\hline Lepidoptera & Bombyx mori & Silkworm & No & 205630 \\
\hline Diptera & Drosophila melanogaster* & Fruit fly & No & 164 \\
\hline Diptera & Aedes aegypti & Mosquito & No & 19731 \\
\hline Hymenoptera & Athaliae rosae & Turnip sawfly & No & 167403 \\
\hline Hymenoptera & Microplitis demolitor* & Parasitoid wasp & No & 251518 \\
\hline Hymenoptera & Nasonia vitripenis* & Parasitoid wasp & No & 20073 \\
\hline Hymenoptera & Nasonia longicornis & Parasitoid wasp & No & 20225 \\
\hline Hymenoptera & Nasonia girulta & Parasitoid wasp & No & 20223 \\
\hline Hymenoptera & Apis meliffera* & Honey bee & Yes & 13343 \\
\hline Hymenoptera & Apis dorsata & Honey bee & Yes & 174631 \\
\hline Hymenoptera & Apis florea & Honey bee & Yes & 86991 \\
\hline Hymenoptera & Bombus impatiens* & Bumble bee & Yes & 70395 \\
\hline Hymenoptera & Bombus terrestris & Bumble bee & Yes & 68545 \\
\hline Hymenoptera & Lasioglossum albipes & Sweat bee & Facultative & 174755 \\
\hline Hymenoptera & Megachile rotundata* & Leafcutter bee & No & 87021 \\
\hline Hymenoptera & Harpegnathos saltator & Jumping ant & Yes & 50203 \\
\hline Hymenoptera & Camponotus floridanus & Carpenter ant & Yes & 50201 \\
\hline Hymenoptera & Atta cephalotes* & Leafcutter ant & Yes & 48091 \\
\hline Hymenoptera & Solenopsis invicta & Fire ant & Yes & 49629 \\
\hline Hymenoptera & Pogonomyrmex barbatus & Harvester ant & Yes & 45797 \\
\hline Hymenoptera & Polistes dominula & Paper wasp & Yes & Unpublished \\
\hline
\end{tabular}

The following genomes were analyzed for the presence or absence of miRNAs. We performed an initial BLAST search of annotated miRNAs from D. melanogaster, A. mellifera, and N. Vitripenis in the species denoted by *. Candidate miRNAs identified as either present only in the genomes of eusocial species (red) or only in Aculeate species (bold), were subsequently analyzed in all genomes listed.

2007; Toth and Robinson, 2007; Bloch and Grozinger, 2011), the actual molecular events that supported traits contributing to eusociality remain elusive. Here, we propose that the molecular evolution of specific miRNAs could have contributed to the phenotypic evolution of eusociality. We propose that these miRNAs may have contributed to the emergence of eusociality by either introducing new regulatory nodes to ancestral behavioral genetic networks, and/or by supporting novel behavioral genetic networks.

The primary sequence of mature miRNAs is often completely conserved across long phylogenetic distances. Consequently, conserved miRNAs are likely to regulate similar target proteincoding genes in distant taxa, and thus support analogous phenotypes across phylogeny (Lee et al., 2007). Given their broad pleiotropic function, novel miRNAs can modify complex developmental or physiological genetic programs. Because of this, it has been suggested by several investigators that, similarly, to the evolution of protein regulatory networks (e.g., evolution of novel transcription factors), novel miRNAs could lead to evolutionary innovations (Sempere et al., 2006; Lee et al., 2007; Niwa and Slack, 2007; Tarver et al., 2012) such as the establishment of new body plans, or novel behavioral traits (Peterson et al., 2009).

Consistent with this premise, the evolution of bilateral animals from eumetazoans was associated with a great expansion in the number of miRNA genes (Niwa and Slack, 2007).
Other examples include the many novel miRNA genes found within placental mammals, and their clade-specific expansion in primates (Sempere et al., 2006). Although the evolution of eusociality is considered a major evolutionary transition event (Maynard Smith and Szathmary, 1995), the hypothesis that it was also associated with the evolution of novel miRNAs has not been previously suggested. We reasoned that the monophyletic Aculeata clade is ideal for testing this hypothesis since, based on current phylogenetic models (Danforth et al., 2013; Johnson et al., 2013), eusociality has independently emerged in this group multiple times (Figure 2). Below we discuss two independent, non-mutually exclusive hypotheses for the possible involvement of miRNAs in the evolution of eusociality.

\section{Hypothesis 1: Specific miRNAs have been Repeatedly Associated with Eusocial Evolution in Hymenoptera}

Here, we hypothesize that, similarly to the evolution of novel transcription factors, the repeated evolution of specific new miRNAs, either de novo or via duplication events, facilitated the evolution of some eusocial traits in multiple independent clades that currently display eusociality. Under this hypothesis, novel miRNAs in current eusocial species act as essential nodes in genetic networks that support eusocial traits. If true, we expect that specific miRNAs would be more likely to be present in the 
genomes of eusocial species in comparison to related solitary species.

As an initial test of this hypothesis, we searched for miRNA genes in the sequenced genomes of species in the Aculeata clade, which includes all living eusocial species in Hymenoptera. We first generated a list of all known annotated miRNA genes available in miRBase for the eusocial honey bee Apis mellifera, the solitary wasp Nasonia vitripennis, and the fruit fly D. melanogaster (Griffiths-Jones et al., 2006). Next, we searched for the presence or absence of each annotated miRNA in several representative hymenopteran genomes (Table 2) using BLASTN (Altschul et al., 1997). We only scored a miRNA as "present" if an exact match to the mature miRNA sequence was found in the genome (Figure 3). Consistent with data from other animal clades (Tarver et al., 2012), we found that most annotated miRNA genes aligned with phylogeny rather than with the presence or absence of eusociality. Nevertheless, five miRNA genes (amemiR-281, ame-miR-306, ame-miR-279c, ame-miR-279d, and ame$m i R-6065)$ seem to be associated with the expression of eusocial traits independent of phylogeny (Figure 3).

To further refine our results, we subsequently extended the bioinformatic analyses to all available sequenced hymenopteran genomes, as well as several non-hymenopteran insect species, which served as outgroups (Figure 4A). Although the low sequence coverage for some of the analyzed ant genomes could lead to higher false-negative discovery rate, we reasoned that the likelihood that certain miRNAs will be falsely missing from all analyzed genomes is very low. Future miRNA sequencing data from many of the species studied here should further help reducing the possibility of false-negatives.

This analysis revealed that three out of the five putative eusociality-associated miRNAs were unique to Hymenoptera (ame-miR-281, ame-miR-306, and ame-miR-279c), and one possibly unique to Aculeata (ame-miR-6065). The phylogenetic distribution of these five miRNAs indicated that multiple eusociality-associated miRNAs might have been gained and lost during the Hymenoptera radiation. In addition, we found that two eusociality-associated miRNA genes (miR-306 and miR6065) were lost in the eusocial wasp Polistes dominula. Markedly, two of the eusocial-related miRNAs ( $m i R-281$ and $m i R-6065)$ were also present in the genome of the facultative eusocial bee Lasioglossum albipes. One possible explanation for this finding is that these specific miRNAs are important for traits associated with basal levels of sociality such as communal living, overlapping generations, and reproductive division of labor (Kocher et al., 2013).

Our analysis also revealed that two of the candidate eusociality-related miRNAs (mir-279c and mir-279d) belong to a single conserved miRNA-family (Cayirlioglu et al., 2008; Hartl et al., 2011; Luo and Sehgal, 2012; Mohammed et al., 2014). The most parsimonious interpretation of these observed phylogenetic patterns is that miR-279d is conserved across Arthropoda, but was lost in Diptera and Hymenoptera, and then reappeared via duplications in eusocial Aculeates. In contrast, $m i R-279 c$ seems to have specifically evolved in Hymenoptera prior to the divergence of Aculeata, and was subsequently lost from nonsocial Aculeate species. The identification of members of the

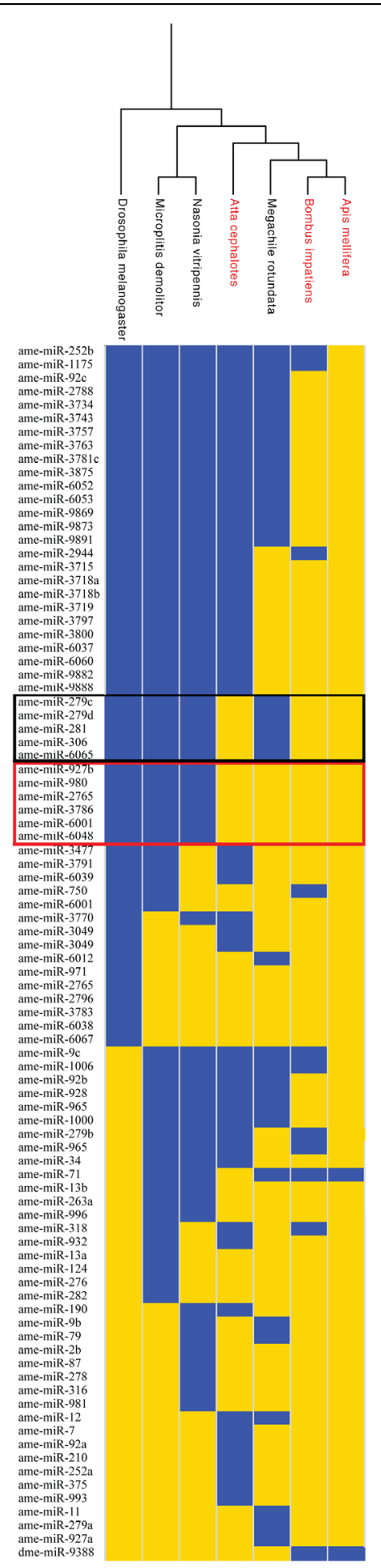

FIGURE 3 | Phylogenetic distributions of miRNAs in Hymenoptera genomes. miRNAs present in each genome are shown in yellow, while those absent are shown in blue. miRNAs present in all or only one species are not shown. Data are clustered based on the phylogenetic relationships between the species analyzed, with eusocial species shown in red. Genes framed in black are present only in eusocial species. Genes framed in red are present only in Aculeata. The fruit fly Drosophila melanogaster served as the outgroup. Phylogeny based on Danforth et al. (2013) and Johnson et al. (2013). 


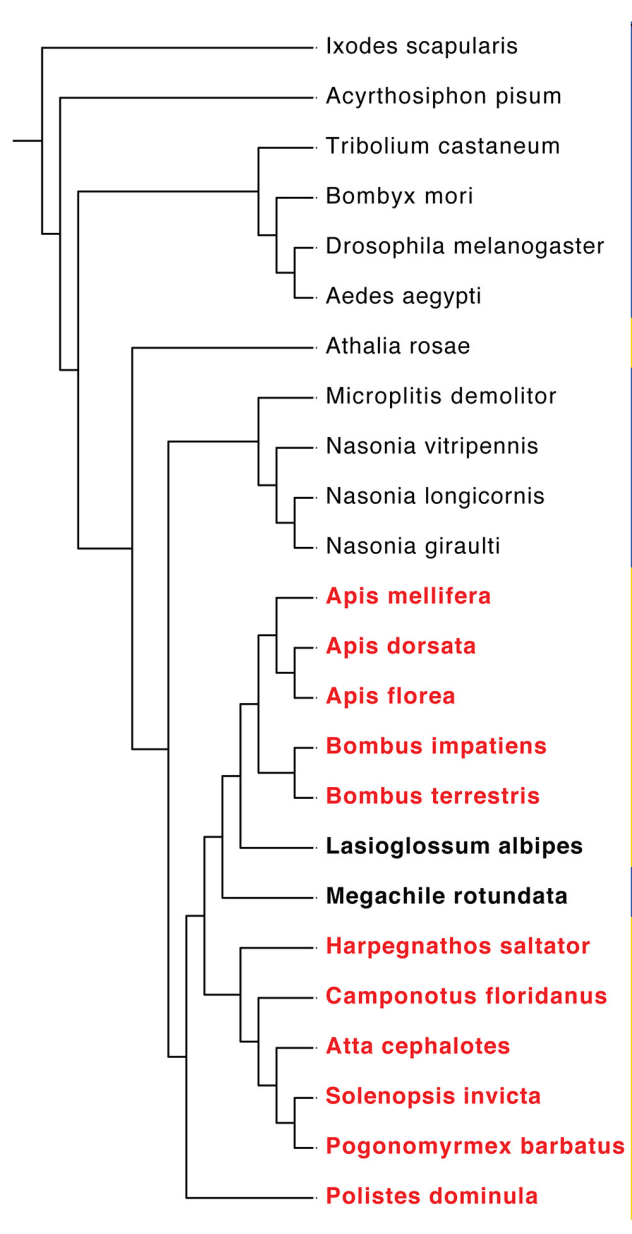

A

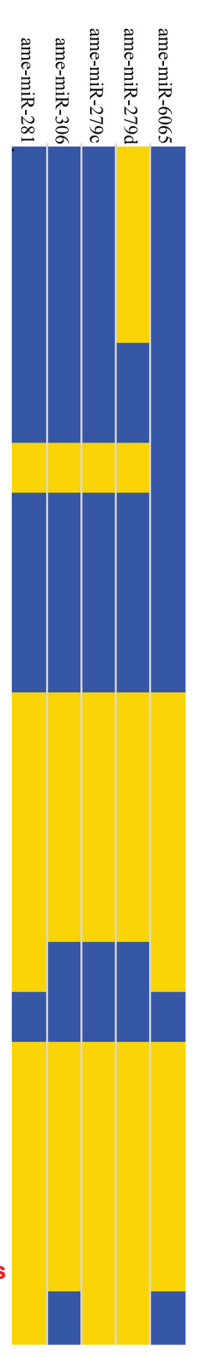

B

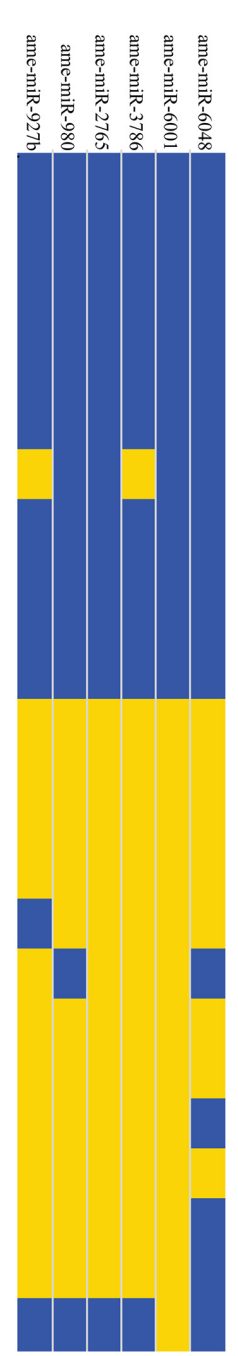

FIGURE 4 | Phylogenetic distributions of Aculeata-specific miRNA. miRNAs present in each genome are shown in yellow, while those absent are shown in blue. (A) High resolution analysis of eusociality-associated candidate miRNAs from Figure 3. (B) High resolution analysis of
Aculeata-spcific candidate miRNAs. Data are clustered based on the phylogenetic relationships between the analyzed genomes, with Aculeate species in bold and eusocial species in red. L. albipes is facultative eusocial. Species phylogeny as in Figure $\mathbf{3}$. mir-279 family as possible candidate genes for the evolution of eusociality is in agreement with findings about their differential regulation between nurses and foragers (Table 1), and possible functions in Drosophila. For example, members of the mir-279 family have been implicated in regulating neuronal development (Hartl et al., 2011), olfactory receptivity (Cayirlioglu et al., 2008; Hartl et al., 2011), and circadian rhythms (Luo and Sehgal, 2012). It is interesting to note that plasticity in both circadian rhythms (Bloch, 2010) and olfactory neurons has been shown to be associated with worker and reproductive divisions of labor in eusocial Hymenoptera (López-Riquelme et al., 2006; Zube and Rössler, 2008; Mysore et al., 2009). Although preliminary, these findings suggest that members of the mir-279 gene family are prime candidates for studies on the possible roles of specific miRNA in the evolution of eusocialityrelated traits.
To further test this hypothesis it will be necessary to increase the phylogenetic resolution of our analyses by studying the miRNA repertoire encoded by the genomes of additional social and solitary insects. It will also require the development of tools that will allow the manipulation of focal miRNA expression to causally determine their effect on behavioral and physiological traits related to eusociality. The recent progress in genomeediting techniques for honey bees and other social insects (Wang et al., 2013; Schulte et al., 2014) suggest that this will be feasible in the near future. Another complementary approach will be to study the protein-coding genetic networks that eusocialityassociated miRNAs are interacting with. By identifying the genes involved, their spatial and temporal expression patterns, and the possible physiological and behavioral processes they modulate, a higher resolution picture of the genetics that support eusociality could emerge. 


\section{Hypothesis 2: Aculeate-Specific miRNAs were Required for Eusocial Evolution}

The second hypothesis we consider is that the presence of specific miRNAs in the pre-eusocial Aculeate genome might have "primed" certain species to evolve eusociality. In other words, specific miRNAs, already present in the genome of the solitary Aculeate ancestor were required, but not sufficient, for the emergence of eusocial traits. Under this hypothesis, specific miRNAs already present in the ancestral solitary aculeate increased the probability of emergence of specific behavioral and physiological traits in response to selective pressures that favored eusociality.

If true, we expect that specific miRNAs should be present in all Aculeate genomes, but absent from all other hymenopteran genomes, as eusociality has never been observed in hymenopteran species outside of the Aculeta. Our initial analysis revealed six Hymenoptera specific miRNA genes (ame-miR-927b, ame-miR-980, ame-miR-2765, ame-miR-3786, ame-miR-6001, and ame-miR-6048; Figure 3). However, two of these genes were were also present in the sawfly Athalia rosae (ame-miR-927b and ame-miR-3786), and therefore are not specific to Aculeata. Three additional genes (ame-miR-980, ame-miR-2765, and ame-miR-6048) appear to have originated after the divergence of Vespidae and therefore did not fulfill the above criteria (Figure 4B). Thus, our analysis revealed amemiR-6001 as the single Aculeate-specific miRNA candidate gene that should be tested in the context of the above hypothesis. Similarly to Hypothesis 1 (see Hypothesis 1: Specific miRNAs have been Repeatedly Associated with Eusocial Evolution in Hymenoptera), the possible role of $m i R-6001$ in the repeated evolution of eusocial traits in Aculeata is hypothetical. Directly testing the hypothesis we put forward here will require extensive molecular, biochemical, and phenotypic studies of its possible physiological and behavioral roles in eusocial traits.

\section{References}

Aboobaker, A., Tomancak, P., Patel, N., Rubin, G. M., and Lai, E. C. (2005). Drosophila microRNAs exhibit diverse spatial expression patterns during embryonic development. Proc. Natl. Acad. Sci. U.S.A. 102, 18017-18022. doi: 10.1073/pnas.0508823102

Adams, H. A., Southey, B. R., Robinson, G. E., and Rodriguez-Zas, S. L. (2008). Meta-analysis of genome-wide expression patterns associated with behavioral maturation in honey bees. BMC Genomics 9:503. doi: 10.1186/1471-2164-9-503

Altschul, S. F., Madden, T. L., Schäffer, A. A., Zhang, J., Zhang, Z., Miller, W., et al. (1997). Gapped BLAST and PSI-BLAST: a new generation of protein database search programs. Nucleic Acids Res. 25, 3389-3402. doi: 10.1093/nar/25.17.3389

Alvarez-Garcia, I., and Miska, E. A. (2005). MicroRNA functions in animal development and human disease. Development 132, 4653-4662. doi: 10.1242/dev.02073

Ament, S. A., Corona, M., Pollock, H. S., and Robinson, G. E. (2008). Insulin signaling is involved in the regulation of worker division of labor in honey bee colonies. Proc. Natl. Acad. Sci. U.S.A. 105, 4226-4231. doi: 10.1073/pnas.0800630105

Andersson, M. (1984). The evolution of eusociality. Annu. Rev. Ecol. Syst. 15, 165-189. doi: 10.1146/annurev.es.15.110184.001121

Bartel, D. P. (2004). MicroRNAs: genomics, biogenesis, mechanism, and function. Cell 116, 281-297. doi: 10.1016/S0092-8674(04)00045-5

Bartel, D. P. (2009). MicroRNAs: target recognition and regulatory functions. Cell 136, 215-233. doi: 10.1016/j.cell.2009.01.002

\section{A Look to the Future}

To date, the majority of data about the function of miRNAs in social insects come from studies of the European honey bee, A. mellifera. Thus, additional molecular and evolutionary analyses of non-hymenopteran eusocial insects as well as other eusocial and solitary clades in the Hymenoptera are required in order to better understand miRNA functions in the context of eusociality. Furthermore, to establish causation between the action of specific miRNAs and eusocial traits, new in vivo genetic and molecular techniques to manipulate social insects are required. Recent advances in molecular genetics of social insects (Yan et al., 2014), and the successful generation of transgenic honey bees (Ben-Shahar, 2014; Schulte et al., 2014), suggest that such studies might be possible in the near future. Furthermore, the development of pharmacological reagents that can block or mimic the action of specific miRNAs (e.g., antagomirs), would represent another important step in that direction (Cristino et al., 2014).

\section{Author Contributions}

ES collected and analyzed genomic data. ES, GB, and YB-S gathered and synthesized relevant literature. ES, GB, and YB-S wrote the manuscript.

\section{Acknowledgments}

We would like to thank Amy Toth for granting us access to unpublished genomic data of $P$. dominula. This work was supported by grants from the US National Science Foundation (1322783) to YB-S and the US-Israel Binational Science Foundation (BSF2012807) to GB.

Bartok, O., Kyriacou, C. P., Levine, J., Sehgal, A., Kadener, S., and B, P. R. S. (2013). Adaptation of molecular circadian clockwork to environmental changes: a role for alternative splicing and miRNAs. Proc. Biol. Sci. 280:20130011. doi: 10.1098/rspb.2013.0011

Behura, S. K., and Whitfield, C. W. (2010). Correlated expression patterns of microRNA genes with age-dependent behavioural changes in honeybee. Insect Mol. Biol. 19, 431-439. doi: 10.1111/j.1365-2583.2010. 01010.x

Ben-Shahar, Y. (2014). A piggyBac route to transgenic honeybees. Proc. Natl. Acad. Sci. U.S.A. 111, 8708-8709. doi: 10.1073/pnas.14078 76111

Berezikov, E. (2011). Evolution of microRNA diversity and regulation in animals. Nat. Rev. Genet. 12, 846-860. doi: 10.1038/nrg3079

Bloch, G. (2010). The social clock of the honeybee. J. Biol. Rhythms 25, 307-317. doi: 10.1177/0748730410380149

Bloch, G., and Grozinger, C. M. (2011). Social molecular pathways and the evolution of bee societies. Philos. Trans. R. Soc. Lond. B Biol. Sci. 366, 21552170. doi: 10.1098/rstb.2010.0346

Bonasio, R., and Shiekhattar, R. (2014). Regulation of transcription by long noncoding RNAs. Annu. Rev. Genet. 48, 433-455. doi: 10.1146/annurev-genet120213-092323

Bonasio, R., Zhang, G., Ye, C., Mutti, N. S., Fang, X., Qin, N., et al. (2010). Genomic comparison of the ants Camponotus floridanus and Harpegnathos saltator. Science 329, 1068-1071. doi: 10.1126/science. 1192428 
Braakman, I., and Bulleid, N. J. (2011). Protein folding and modification in the mammalian endoplasmic reticulum. Annu. Rev. Biochem. 80, 71-99. doi: 10.1146/annurev-biochem-062209-093836

Breitbart, R. E., Andreadis, A., and Nadal-Ginard, B. (1987). Alternative splicing: a ubiquitous mechanism for the generation of multiple protein isoforms from single genes. Annu. Rev. Biochem. 56, 467-495. doi: 10.1146/annurev.bi.56.070187.002343

Bryant, B., Macdonald, W., and Raikhel, A. S. (2010). microRNA miR275 is indispensable for blood digestion and egg development in the mosquito Aedes aegypti. Proc. Natl. Acad. Sci. U.S.A. 107, 22391-22398. doi: 10.1073/pnas.1016230107

Bushati, N., and Cohen, S. M. (2007). microRNA functions. Annu. Rev. Cell Dev. Biol. 23, 175-205. doi: 10.1146/annurev.cellbio.23.090506. 123406

Cao, X., Pfaff, S. L., and Gage, F. H. (2007). A functional study of miR124 in the developing neural tube A functional study of miR-124 in the developing neural tube. Genes Dev. 21, 531-536. doi: 10.1101/gad.15 19207

Cayirlioglu, P., Kadow, I. G., Zhan, X., Okamura, K., Suh, G. S. B., Gunning, D., et al. (2008). Hybrid neurons in a microRNA mutant are putative evolutionary intermediates in insect CO2 sensory systems. Science 319, 1256-1260. doi: $10.1126 /$ science. 1149483

Chiba, S. (2006). Notch signaling in stem cell systems. Stem Cells 24, 2437-2447. doi: 10.1634/stemcells.2005-0661

Clark, A. M., Goldstein, L. D., Tevlin, M., Tavaré, S., Shaham, S., and Miska, E. A. (2010). The microRNA miR-124 controls gene expression in the sensory nervous system of Caenorhabditis elegans. Nucleic Acids Res. 38, 3780-3793. doi: 10.1093/nar/gkq083

Crespi, B. J., and Yanega, D. (1995). The definition of eusociality. Behav. Ecol. 6, 109-115. doi: 10.1093/beheco/6.1.109

Crick, F. (1970). Central dogma of molecular biology. Nature 227, 561-563. doi: 10.1038/227561a0

Cristino, A. S., Barchuk, A. R., Freitas, F. C. P., Narayanan, R. K., Biergans, S. D., Zhao, Z., et al. (2014). Neuroligin-associated microRNA-932 targets actin and regulates memory in the honeybee. Nat. Commun. 5, 5529. doi: $10.1038 /$ ncomms6529

Danforth, B. N., Cardinal, S., Praz, C., Almeida, E. A., and Michez, D. (2013). The impact of molecular data on our understanding of bee phylogeny and evolution. Annu. Rev. Entomol. 58, 57-78. doi: 10.1146/annurev-ento-120811153633

Daugherty, T. H. F., Toth, A. L., and Robinson, G. E. (2011). Nutrition and division of labor: effects on foraging and brain gene expression in the paper wasp Polistes metricus. Mol. Ecol. 20, 5337-5347. doi: 10.1111/j.1365-294X.2011. 05344.x

Denison, R., and Raymond-Delpech, V. (2008). Insights into the molecular basis of social behaviour from studies on the honeybee, Apis mellifera. Invertebr. Neurosci. 8, 1-9. doi: 10.1007/s10158-008-0066-6

Fiore, R., Khudayberdiev, S., Saba, R., and Schratt, G. (2011). MicroRNA function in the nervous system. Prog. Mol. Biol. Transl. Sci. 102, 47-100. doi: 10.1016/B978-0-12-415795-8.00004-0

Fischman, B. J., Woodard, S. H., and Robinson, G. E. (2011). Molecular evolutionary analyses of insect societies. Proc. Natl. Acad. Sci. U.S.A. 108, 10847-10854. doi: 10.1073/pnas.1100301108

Foret, S., Kucharski, R., Pellegrini, M., Feng, S., Jacobsen, S. E., Robinson, G. E., et al. (2012). DNA methylation dynamics, metabolic fluxes, gene splicing, and alternative phenotypes in honey bees. Proc. Natl. Acad. Sci. U.S.A. 109, 4968-4973. doi: 10.1073/pnas.1202392109

Gascon, E., Lynch, K., Ruan, H., Almeida, S., Verheyden, J. M., Seeley, W. W., et al. (2014). Alterations in microRNA-124 and AMPA receptors contribute to social behavioral deficits in frontotemporal dementia. Nat. Med. 20, 1444-1451. doi: 10.1038/nm.3717

Gott, J. M., and Emeson, R. B. (2000). Functions and mechanisms of RNA editing. Annu. Rev. Genet. 34, 499-531. doi: 10.1146/annurev.genet.34. 1.499

Greenberg, J. K., Xia, J., Zhou, X., Thatcher, S. R., Gu, X., Ament, S. A., et al. (2012). Behavioral plasticity in honey bees is associated with differences in brain microRNA transcriptome. Genes Brain Behav. 11, 660-670. doi: 10.1111/j.1601183X.2012.00782.X
Griffiths-Jones, S., Grocock, R. J., van Dongen, S., Bateman, A., and Enright, A. J. (2006). miRBase: microRNA sequences, targets and gene nomenclature. Nucleic Acids Res. 34, D140-D144. doi: 10.1093/nar/gkj112

Guo, X., Su, S., Skogerboe, G., Dai, S., Li, W., Li, Z., et al. (2013). Recipe for a busy bee: microRNAs in honey bee caste determination. PLOS ONE 8:e81661. doi: 10.1371/journal.pone.0081661

Hamilton, W. D. (1964). The genetical evolution of social behaviour: I, II. J. Theor. Biol. 7, 1-52. doi: 10.1016/0022-5193(64)90038-4

Hartl, M., Loschek, L. F., Stephan, D., Siju, K. P., Knappmeyer, C., and Kadow, I. C. G. (2011). A new Prospero and microRNA-279 pathway restricts CO2 receptor neuron formation. J. Neurosci. 31, 15660-15673. doi: 10.1523/JNEUROSCI.2592-11.2011

Heisenberg, M. (2003). Mushroom body memoir: from maps to models. Nat. Rev. Neurosci. 4, 266-275. doi: 10.1038/nrn1074

Hölldobler, B., and Wilson, E. O. (2009). The Superorganism: The Beauty, Elegance, and Strangeness of Insect Societies. New York, NY: W.W. Norton.

Impey, S., Davare, M., Lesiak, A., Lasiek, A., Fortin, D., Ando, H., et al. (2010). An activity-induced microRNA controls dendritic spine formation by regulating Racl-PAK signaling. Mol. Cell. Neurosci. 43, 146-156. doi: 10.1016/j.mcn.2009.10.005

Johnson, B. R., Borowiec, M. L., Chiu, J. C., Lee, E. K., Atallah, J., and Ward, P. S. (2013). Phylogenomics resolves evolutionary relationships among ants, bees, and wasps. Curr. Biol. 23, 2058-2062. doi: 10.1016/j.cub.2013. 08.050

Keller, L., and Ross, K. G. (1998). Selfish genes: a green beard in the red fire ant. Nature 394, 573-575. doi: 10.1038/29064

Kim, B., Kim, K. W., and Choe, J. C. (2012). Temporal polyethism in korean yellowjacket foragers, Vespula koreensis (Hymenoptera, Vespidae). Insectes Soc. 59, 263-268. doi: 10.1007/s00040-011-0212-8

Kim, J., Inoue, K., Ishii, J., Vanti, W. B., Voronov, S. V., Murchison, E., et al. (2007). A microRNA feedback circuit in midbrain dopamine neurons. Science 317, 1220-1224. doi: 10.1126/science.1140481

Kocher, S. D., Li, C., Yang, W., Tan, H., Yi, S. V., Yang, X., et al. (2013). The draft genome of a socially polymorphic halictid bee, Lasioglossum albipes. Genome Biol. 14:R142. doi: 10.1186/gb-2013-14-12-r142

Lai, E. C., Tam, B., and Rubin, G. M. (2005). Pervasive regulation of Drosophila Notch target genes by GY-box-, Brd-box-, and K-box-class microRNAs. Genes Dev. 19, 1067-1080. doi: 10.1101/gad.1291905

Lee, C.-T., Risom, T., and Strauss, W. M. (2007). Evolutionary conservation of microRNA regulatory circuits: an examination of microRNA gene complexity and conserved microRNA-target interactions through metazoan phylogeny. DNA Cell Biol. 26, 209-218. doi: 10.1089/dna.200 6.0545

Lee, R. C., Feinbaum, R. L., and Ambros, V. (1993). The C. elegans heterochronic gene lin-4 encodes small RNAs with antisense complementarity to lin-14. Cell 75, 843-854. doi: 10.1016/0092-8674(93)90529-Y

Lee, T., and Young, R. (2000). Transcription of eukaryotic protein-coding genes. Annu. Rev. Genet. 34, 77-137. doi: 10.1146/annurev.genet. 34.1.77

Li, W., Cressy, M., Qin, H., Fulga, T., Van Vactor, D., and Dubnau, J. (2013). MicroRNA-276a functions in ellipsoid body and mushroom body neurons for naive and conditioned olfactory avoidance in Drosophila. J. Neurosci. 33, 5821-5833. doi: 10.1523/JNEUROSCI.4004-12.2013

Liu, F., Li, W., Li, Z., Zhang, S., Chen, S., and Su, S. (2011). High-abundance mRNAs in Apis mellifera: comparison between nurses and foragers. J. Insect Physiol. 57, 274-279. doi: 10.1016/j.jinsphys.2010.11.015

Liu, F., Peng, W., Li, Z., Li, W., Li, L., Pan, J., et al. (2012). Next-generation small RNA sequencing for microRNAs profiling in Apis mellifera: comparison between nurses and foragers. Insect Mol. Biol. 21, 297-303. doi: 10.1111/j.13652583.2012.01135.x

López-Riquelme, G. O., Malo, E. A., Cruz-López, L., and Fanjul-Moles, M. L. (2006). Antennal olfactory sensitivity in response to taskrelated odours of three castes of the ant Atta mexicana (hymenoptera: formicidae). Physiol. Entomol. 31, 353-360. doi: 10.1111/j.1365-3032.2006. 00526.x

Louvi, A., and Artavanis-Tsakonas, S. (2006). Notch signalling in vertebrate neural development. Nat. Rev. Neurosci. 7, 93-102. doi: 10.1038/nr n1847 
Luo, W., and Sehgal, A. (2012). Regulation of circadian behavioral output via a microRNA-JAK/STAT circuit. Cell 148, 765-779. doi: 10.1016/j.cell.2011. 12.024

Makeyev, E. V., Zhang, J., Carrasco, M. A., and Maniatis, T. (2007). The microRNA miR-124 promotes neuronal differentiation by triggering brain-specific alternative pre-mRNA splicing. Mol. Cell 27, 435-448. doi: 10.1016/j.molcel.2007.07.015

Maynard Smith, J., and Szathmary, E. (1995). The Major Transitions in Evolution. Oxford: Oxford University Press.

McNeill, E., and Van Vactor, D. (2012). MicroRNAs shape the neuronal landscape. Neuron 75, 363-379. doi: 10.1016/j.neuron.2012.07.005

Mohammed, J., Siepel, A., and Lai, E. C. (2014). Diverse modes of evolutionary emergence and flux of conserved microRNA clusters. RNA 20, 1850-1863. doi: 10.1261/rna.046805.114

Morita, S., Horii, T., Kimura, M., and Hatada, I. (2013). MiR-184 regulates insulin secretion through repression of Slc25a22. PeerJ 1:e162. doi: 10.7717/pee rj. 162

Mysore, K., Subramanian, K. A., Sarasij, R. C., Suresh, A., Shyamala, B. V., VijayRaghavan, K., et al. (2009). Caste and sex specific olfactory glomerular organization and brain architecture in two sympatric ant species Camponotus sericeus and Camponotus compressus (Fabricius, 1798). Arthropod. Struct. Dev. 38, 485-497. doi: 10.1016/j.asd.2009. 06.001

Na, Y. J., Sung, J. H., Lee, S. C., Lee, Y. J., Choi, Y. J., Park, W. Y., et al. (2009). Comprehensive analysis of microRNA-mRNA co-expression in circadian rhythm. Exp. Mol. Med. 41, 638-647. doi: 10.3858/emm.2009.41. 9.070

Naug, D., and Gadagkar, R. (1998). The role of age in temporal polyethism in a primitively eusocial wasp. Behav. Ecol. Sociobiol. 42, 37-47. doi: $10.1007 / \mathrm{s} 002650050409$

Niwa, R., and Slack, F. J. (2007). The evolution of animal microRNA function. Curr. Opin. Genet. Dev. 17, 145-150. doi: 10.1016/j.gde.2007.02.004

Nowak, M. A., Tarnita, C. E., and Wilson, E. O. (2010). The evolution of eusociality. Nature 466, 1057-1062. doi: 10.1038/nature09205

Oxley, P. R., Ji, L., Fetter-Pruneda, I., McKenzie, S. K., Li, C., Hu, H., et al. (2014). The genome of the Clonal raider ant Cerapachys biroi. Curr. Biol. 24, 451-458. doi: 10.1016/j.cub.2014.01.018

Page, R. E., and Amdam, G. V. (2007). The making of a social insect: developmental architectures of social design. Bioessays 29, 334-343. doi: 10.1002/bies.20549

Paroo, Z., Ye, X., Chen, S., and Liu, Q. (2009). Phosphorylation of the human microRNA-generating complex mediates MAPK/Erk signaling. Cell 139, 112122. doi: $10.1016 /$ j.cell.2009.06.044

Peeters, C., Liebig, J., and Hölldobler, B. (2000). Sexual reproduction by both queens and workers in the ponerine ant Harpegnathos saltator. Insectes Soc. 47, 325-332. doi: 10.1007/PL00001724

Peterson, K. J., Dietrich, M. R., and McPeek, M. A. (2009). MicroRNAs and metazoan macroevolution: insights into canalization, complexity, and the Cambrian explosion. Bioessays 31, 736-747. doi: 10.1002/bies.200900033

Qin, Q.-H., Wang, Z.-L., Tian, L.-Q., Gan, H.-Y., Zhang, S.-W., and Zeng, Z.-J. (2013). The integrative analysis of microRNA and mRNA expression in Apis mellifera following maze-based visual pattern learning. Insect Sci. 21, 619-636. doi: 10.1111/1744-7917.12065

Qureshi, I. A., and Mehler, M. F. (2012). Emerging roles of non-coding RNAs in brain evolution, development, plasticity and disease. Nat. Rev. Neurosci. 13, 528-541. doi: 10.1038/nrn3234

Rajasethupathy, P., Fiumara, F., Sheridan, R., Betel, D., Puthanveettil, S. V., Russo, J. J., et al. (2009). Characterization of small RNAs in Aplysia reveals a role for miR-124 in constraining synaptic plasticity through CREB. Neuron 63, 803-817. doi: 10.1016/j.neuron.2009.05.029

Robinson, G. E. (1992). Regulation of division of labor in insect societies. Annu. Rev. Entomol. 37, 637-665. doi: 10.1146/annurev.en.37.010192.003225

Robinson, G. E., Fahrbach, S. E., and Mark, L. (1997). Insect societies and the molecular biology of social behavior. Bioessays 19, 1099-1108. doi: 10.1002/bies.950191209

Robinson, G. E., Grozinger, C. M., and Whitfield, C. W. (2005). Sociogenomics: social life in molecular terms. Nat. Rev. Genet. 6, 257-270. doi: 10.1038/nrg1575

Schratt, G. (2009). microRNAs at the synapse. Nat. Rev. Neurosci. 10, 842-849. doi: $10.1038 / \mathrm{nrn} 2763$
Schratt, G. M., Tuebing, F., Nigh, E. A., Kane, C. G., Sabatini, M. E., Kiebler, M., et al. (2006). A brain-specific microRNA regulates dendritic spine development. Nature 439, 283-289. doi: 10.1038/nature04367

Schulte, C., Theilenberg, E., Müller-Borg, M., Gempe, T., and Beye, M. (2014). Highly efficient integration and expression of piggyBac-derived cassettes in the honeybee (Apis mellifera). Proc. Natl. Acad. Sci. U.S.A. 111, 9003-9008. doi: $10.1073 /$ pnas.1402341111

Schwander, T., Lo, N., Beekman, M., Oldroyd, B. P., and Keller, L. (2010). Nature versus nurture in social insect caste differentiation. Trends Ecol. Evol. 25, 275-282. doi: 10.1016/j.tree.2009.12.001

Sempere, L. F., Cole, C. N., McPeek, M. A., and Peterson, K. J. (2006). The phylogenetic distribution of metazoan microRNAs: insights into evolutionary complexity and constraint. J. Exp. Zool. B Mol. Dev. Evol. 306, 575-588. doi: $10.1002 /$ jez.b. 21118

Shi, Y.-Y., Zheng, H.-J., Pan, Q.-Z., Wang, Z.-L., and Zeng, Z.-J. (2014). Differentially expressed microRNAs between queen and worker larvae of the honey bee (Apis mellifera). Apidologie 46, 35-45. doi: 10.1007/s13592-0140299-9

Siegel, G., Saba, R., and Schratt, G. (2011). microRNAs in neurons: manifold regulatory roles at the synapse. Curr. Opin. Genet. Dev. 21, 491-497. doi: 10.1016/j.gde.2011.04.008

Smith, C. R., Toth, A. L., Robinson, G. E., and Suarez, A. V. (2008). Genetic and genomic analyses of the division of labour in insect societies. Nat. Rev. Genet. 9, 735-748. doi: $10.1038 / \mathrm{nrg} 2429$

Tarver, J. E., Donoghue, P. C. J., and Peterson, K. J. (2012). Do miRNAs have a deep evolutionary history? Bioessays 34, 857-866. doi: 10.1002/bies.201 200055

Toth, A. L., and Robinson, G. E. (2007). Evo-devo and the evolution of social behavior. Trends Genet. 23, 334-341. doi: 10.1016/j.tig.2007. 05.001

Wang, Y., Li, Z., Xu, J., Zeng, B., Ling, L., You, L., et al. (2013). The CRISPR/Cas system mediates efficient genome engineering in Bombyx mori. Cell Res. 23, 1414-1416. doi: 10.1038/cr.2013.146

Weaver, D. B., Anzola, J. M., Evans, J. D., Reid, J. G., Reese, J. T., Childs, K. L., et al. (2007). Computational and transcriptional evidence for microRNAs in the honey bee genome. Genome Biol. 8:R97. doi: 10.1186/gb-20078-6-r97

Weinstock, G. M., Robinson, G. E., Gibbs, R. A., Worley, K. C., Evans, J. D., Maleszka, R., et al. (2006). Insights into social insects from the genome of the honeybee Apis mellifera. Nature 443, 931-949. doi: 10.1038/nature 05260

Whitfield, C. W., Cziko, A.-M., and Robinson, G. E. (2003). Gene expression profiles in the brain predict behavior in individual honey bees. Science 302, 296-299. doi: 10.1126/science. 1086807

Wienholds, E., Kloosterman, W. P., Miska, E., Alvarez-Saavedra, E., Berezikov, E., de Bruijn, E., et al. (2005). MicroRNA expression in zebrafish embryonic development. Science 309, 310-311. doi: 10.1126/science. 1114519

Wienholds, E., and Plasterk, R. H. A. (2005). MicroRNA function in animal development. FEBS Lett. 579, 5911-5922. doi: 10.1016/j.febslet.2005.07.070

Wilson, E. (1990). Success and Dominance in Ecosystems: The Case of the Social Insects. Oldendorf/Luhe: Ecology Institute.

Wilson, E. O. (1985). The sociogenesis of insect colonies. Science 228, 1489-1495. doi: 10.1126/science.228.4707.1489

Winston, M. L. (1987). The Biology of the Honey Bee. Cambridge, MA: Harvard University Press.

Wolschin, F., Mutti, N. S., and Amdam, G. V. (2011). Insulin receptor substrate influences female caste development in honeybees. Biol. Lett. 7, 112-115. doi: $10.1098 / \mathrm{rsbl} .2010 .0463$

Woodard, S. H., Fischman, B. J., Venkat, A., Hudson, M. E., Varala, K., Cameron, S. A., et al. (2011). Genes involved in convergent evolution of eusociality in bees. Proc. Natl. Acad. Sci. U.S.A. 108, 7472-7477. doi: 10.1073/pnas.1103 457108

Woyke, J. (1955). Multiple mating of the honeybee queen (Apis mellifica L.) in one nuptial flight. Bull. Acad. Polon. Sci. 3, 175-180.

Wu, C.-I., Shen, Y., and Tang, T. (2009). Evolution under canalization and the dual roles of microRNAs: a hypothesis. Genome Res. 19, 734-743. doi: 10.1101 /gr.084640.108 
Wu, X., Wang, Z., Zhang, F., Shi, Y., and Zeng, Z. (2014). Mating flight causes genome-wide transcriptional changes in sexually mature honeybee queens. J. Asia Pac. Entomol. 17, 37-43. doi: 10.1016/j.aspen.2013.10.001

Yan, H., Bonasio, R., Simola, D. F., Liebig, J., Berger, S. L., and Reinberg, D. (2015). DNA methylation in social insects: how epigenetics can control behavior and longevity. Annu. Rev. Entomol. 60, 435-452. doi: 10.1146/annurev-ento010814-020803

Yan, H., Simola, D. F., Bonasio, R., Liebig, J., Berger, S. L., and Reinberg, D. (2014). Eusocial insects as emerging models for behavioural epigenetics. Nat. Rev. Genet. 15, 677-688. doi: 10.1038/nrg3787

Zhu, Q.-Y., Liu, Q., Chen, J.-X., Lan, K., and Ge, B.-X. (2010). MicroRNA101 targets MAPK phosphatase-1 to regulate the activation of MAPKs in macrophages. J. Immunol. 185, 7435-7442. doi: 10.4049/jimmunol. 1000798
Zube, C., and Rössler, W. (2008). Caste- and sex-specific adaptations within the olfactory pathway in the brain of the ant Camponotus floridanus. Arthropod. Struct. Dev. 37, 469-479. doi: 10.1016/j.asd.2008.05.004

Conflict of Interest Statement: The authors declare that the research was conducted in the absence of any commercial or financial relationships that could be construed as a potential conflict of interest.

Copyright (c) 2015 Søvik, Bloch and Ben-Shahar. This is an open-access article distributed under the terms of the Creative Commons Attribution License (CC BY). The use, distribution or reproduction in other forums is permitted, provided the original author(s) or licensor are credited and that the original publication in this journal is cited, in accordance with accepted academic practice. No use, distribution or reproduction is permitted which does not comply with these terms. 